\title{
Plasticized Biodegradable Poly(lactic acid) Based Composites Containing Cellulose in Micro- and Nanosize
}

\author{
Katalin Halász and Levente Csóka \\ Institute of Wood and Paper Technologies, Faculty of Wood Sciences, University of West Hungary, 9400 Sopron, Hungary \\ Correspondence should be addressed to Katalin Halász; hakat@sopron.nyme.hu
}

Received 28 August 2012; Revised 8 November 2012; Accepted 9 November 2012

Academic Editor: Ying-Ling Liu

Copyright (C) 2013 K. Halász and L. Csóka. This is an open access article distributed under the Creative Commons Attribution License, which permits unrestricted use, distribution, and reproduction in any medium, provided the original work is properly cited.

The aim of this work was to study the characteristics of thermal processed poly(lactic acid) composites. Poly(ethylene glycol) (PEG400), microcrystalline cellulose (MCC), and ultrasound-treated microcrystalline cellulose (USMCC) were used in 1, 3, and 5 weight percents to modify the attributes of PLA matrix. The composite films were produced by twin screw extrusion followed by film extrusion. The manufactured PLA-based films were characterized by tensile testing, differential scanning calorimetry (DSC), scanning electron microscopy (SEM), wide angle X-ray diffraction (WAXD), and degradation test.

\section{Introduction}

Poly(lactic acid) or PLA is a biobased thermoplastic polyester which can be produced from lactic acid derived from the fermentation of different naturally available polysaccharides. Furthermore, PLA is a biodegradable and compostable plastic with relative good properties compared to the other biodegradable, biobased plastics, thus PLA has got its potential in many applications such as in medical, drug delivery, and textile or packaging applications. However, PLA is too brittle for many applications, softens at relative low temperatures, and has weak water vapor and gas barrier properties compared to commercial polymers. To extend the application field the improvement of its properties (barrier, thermal, and mechanical) is required.

Many efforts have been taken to improve the week properties of PLA with different kind of materials including blending/compounding with other polymers, plasticizers, [1-4] reinforcing materials in micro- (e.g., natural fibers, particles) and nanosize (layered silicates, carbon nanotubes, nanoparticles, or nanocrystals) [5-9]. One of the most promising material to improve the properties of the PLA can be the cellulose [10-13]. Cellulose is the most abundant renewable, biodegradable polymer on the Earth, and its properties give a widespread industrial usage. Cellulose bears relatively reactive surface, thus it can be a good choice at producing PLA-based green composites/nanocomposites. Microcrystalline (MCC) and nanocrystalline cellulose can be both applied for improving the properties of PLA. Microcrystalline cellulose is commercially available cellulose nanocrystal, on the other hand it is not yet a commercially available product, but it can be achieved from MCC via acidic hydrolysis and/or ultrasonical (US), hydrodynamical cavitation treatment [14-16]. It is necessary to mention that processing techniques have a remarkable impact on the adhesion properties of the resulting cellulose in composite/nanocomposite applications [17]. Processability and properties of composites or nanocomposites are strongly affected by four main factors, which are characters of the components, composition, interfacial interactions, and structure [18]. Using cellulose has got its limitations because cellulose or nanocellulose has a strong sensitivity to water and moisture, when it is dried it may form aggregates and display poor compatibility with the hydrophobic polymeric matrices. The polar surface of cellulose makes difficulties in uniform dispersion in apolar plastics. Although PLA is an apolar synthetic polymer it contains polar groups like $\mathrm{C}=\mathrm{O}$ as well, which can help the interactions, for example the hydrogen 


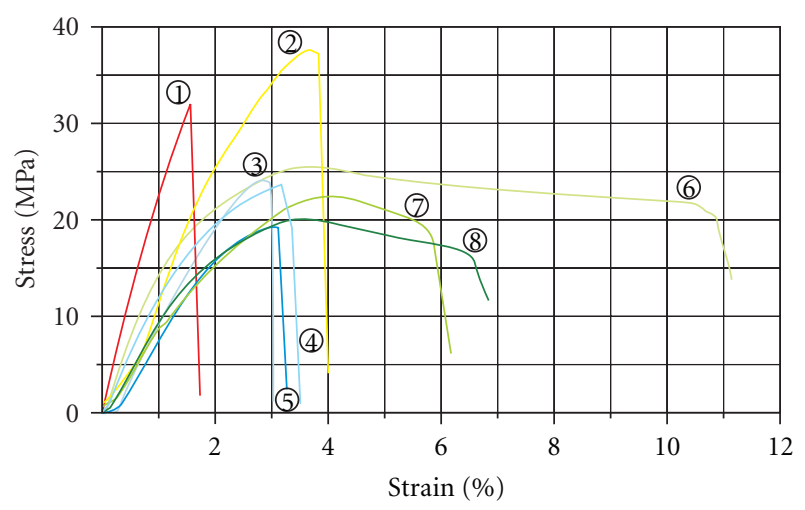

FIGURE 1: Stress-strain curves in machine direction.

bond formation between cellulose $\mathrm{OH}$ and PLA C $=\mathrm{O}$ groups [19]. Interfacial interactions can be improved by different kind of physical (corona, plasma, laser, or $\gamma$ radiation) and chemical treatments [10]. Compatibilizers such as alcene ketene dimmer, maleic-anhydride, phenyltrimethoxysilican, or poly(ethylene glycol) can provide stronger interactions as well. Poly(ethylene glycol) (PEG) can improve the interfacial interactions between PLA and cellulose, the $\mathrm{C}-\mathrm{O}-\mathrm{C}$, and the $\mathrm{O}-\mathrm{H}$ of the PEG can form $\mathrm{H}$-bonding or dipolar interactions between matrix and reinforcing material [13]. PEG can not only act as compatibilizer but as plasticizer as well thus reducing the brittleness of the PLA. In general, the lower the molecular weight the higher the plasticizing effect [2, 20, 21]. PEGs with lower molecular weights have larger number of hydroxyl groups per mole compared to the PEGs with higher molecular weights. The -OH groups of the PEG chains are believed to develop hydrogen bonds between the polymer and the plasticizer replacing the polymer-polymer interactions [21], [22]. Additionally to the higher plasticizing effect of low molecular weight poly(ethylene glycol), PEGs in liquid form can help the uniform dispersion of the cellulose preventing the cellulose feeding difficulties into the extruder during the melt compounding.

In this paper the effects of microcrystalline cellulose with and without ultrasound treatment and PEG 400 on the properties of the poly(lactic acid) produced by melt process were studied.

\section{Experimental}

2.1. Materials and Methods. Poly(lactic acid) transparent, extrusion grade granulate was supplied from Shenzhen Bright China Industrial Co. with trade name Esun; microcrystalline cellulose was obtained from Sigma Aldrich in particle size $<20 \mu \mathrm{m}$. Poly(ethylene glycol) was received from Sigma Aldrich and used in liquid form with the average molecular weight of 400 .

Since hydrolytic degradation of PLA can appear during the extrusion [23], PLA and MCC were properly dried (at $60^{\circ} \mathrm{C}$ for 4 day) prior to all the used processing technologies. The components (microcrystalline cellulose with and

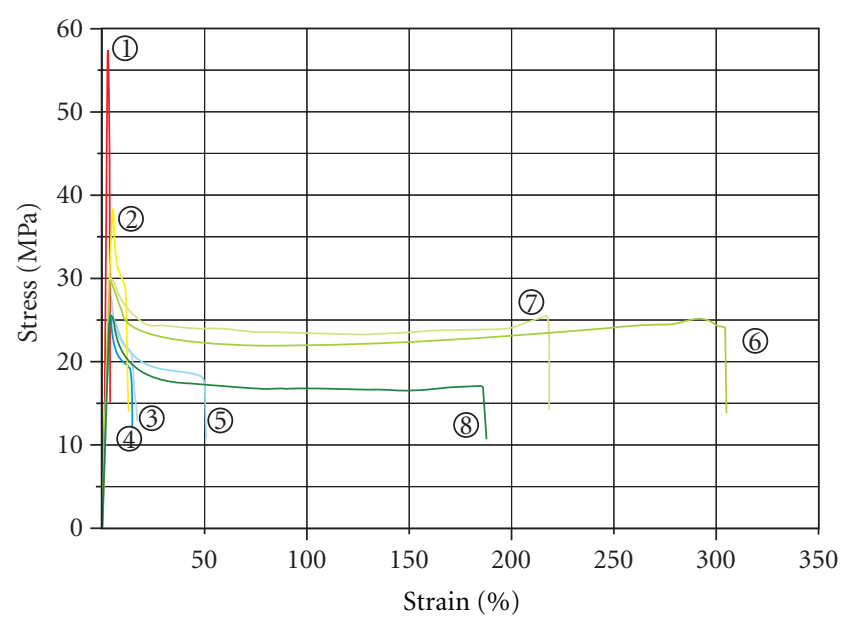

FIGURE 2: Stress-strain curves in cross direction.

TABLE 1: Characterized materials.

\begin{tabular}{|c|c|}
\hline (1) & neat PLA \\
\hline$(2)$ & PLA + $10 w t \%$ PEG \\
\hline (3) & PLA + $1 w t \%$ MMC + $10 w t \%$ PEG \\
\hline (4) & PLA + $3 w t \%$ MMC + $10 w t \%$ PEG \\
\hline (5) & PLA + $5 w t \%$ MMC + $10 w t \%$ PEG \\
\hline (6) & PLA + $1 w t \%$ USMMC + $10 w t \%$ PEG \\
\hline (7) & PLA + $3 w t \%$ USMMC + $10 w t \%$ PEG \\
\hline (8) & PLA + $5 w t \%$ USMMC + $10 w t \%$ PEG \\
\hline
\end{tabular}

without ultrasound treatment at 1,3 , and 5 weight percent, poly(ethylene glycol) at 10 weight percent) were mixed in a COLLIN ZK25T four zoned compact laboratory twin screw corotating extruder with a screw speed of $50 \mathrm{rpm}$, and the temperature profile varied from $170^{\circ} \mathrm{C}$ at the feeding zone to $190^{\circ} \mathrm{C}$ at the die. The composite films (Table 1) were prepared on a twin screw extruder (LABTECH Scientific twin screw extruder with melt pump and LBRC -150 chill roll cast line) in the thickness of 90-110 microns. PEG400 which is a nontoxic, neutral, nonvolatile, nonirritating material was used as plasticizer, compatibilizer, and as dispersion helper as well. To indicate particle size reduction and to help the dispersion of the cellulose the MCC-PEG suspension was treated in an ultrasonic bath (with dual-frequency unit transducers frequencies of 25 and $75 \mathrm{kHz}$ ) for $40 \mathrm{~min}$. To obtain nanosized cellulose chemicals were not used in order to keep the process "green". Control samples were prepared through the above-mentioned processes.

2.2. Characterizations. The tensile properties of the samples were measured both in cross and production direction according to EN 527 using Istron 3345 tensile tester. The measurements were performed at $23^{\circ} \mathrm{C}$ and $50 \mathrm{RH} \%$, with $50 \mathrm{~mm}$ gauge length, $2 \mathrm{kN}$ max. load, and $50 \mathrm{~mm} / \mathrm{min}$ crosshead speed. Young-modulus, stress, and strain at peak and at break 


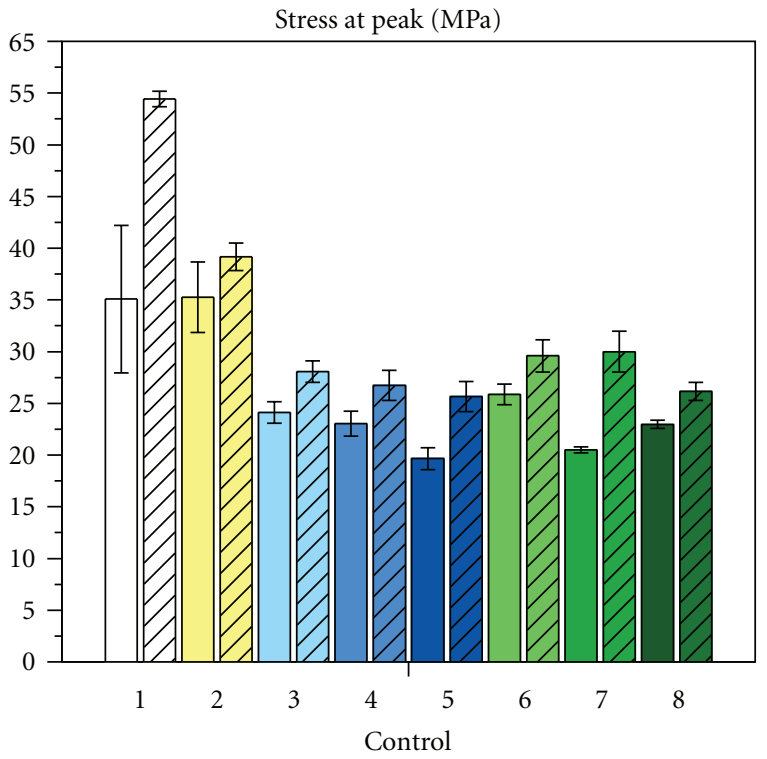

Machine direction $\square$ Cross direction

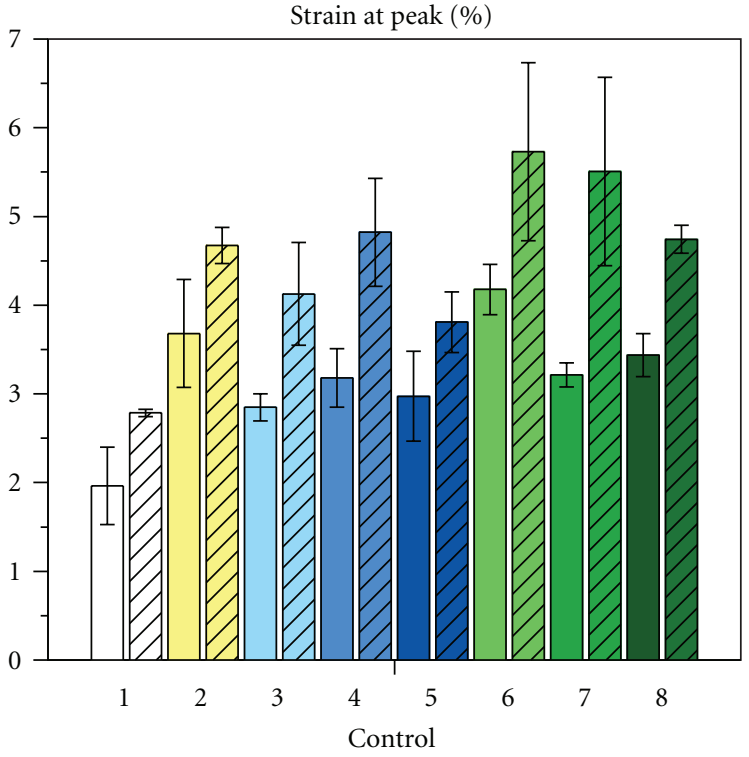

Machine direction $\square$ Cross direction

(a)

(b)

FIGURE 3: Stress at peak and strain at peak in machine and in cross directions.

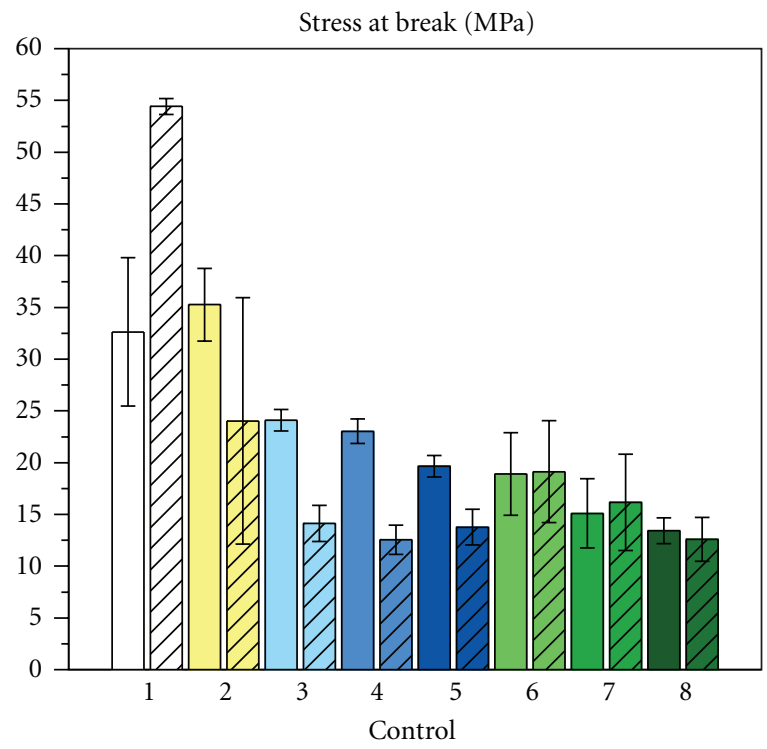

Machine direction $\square$ Cross direction

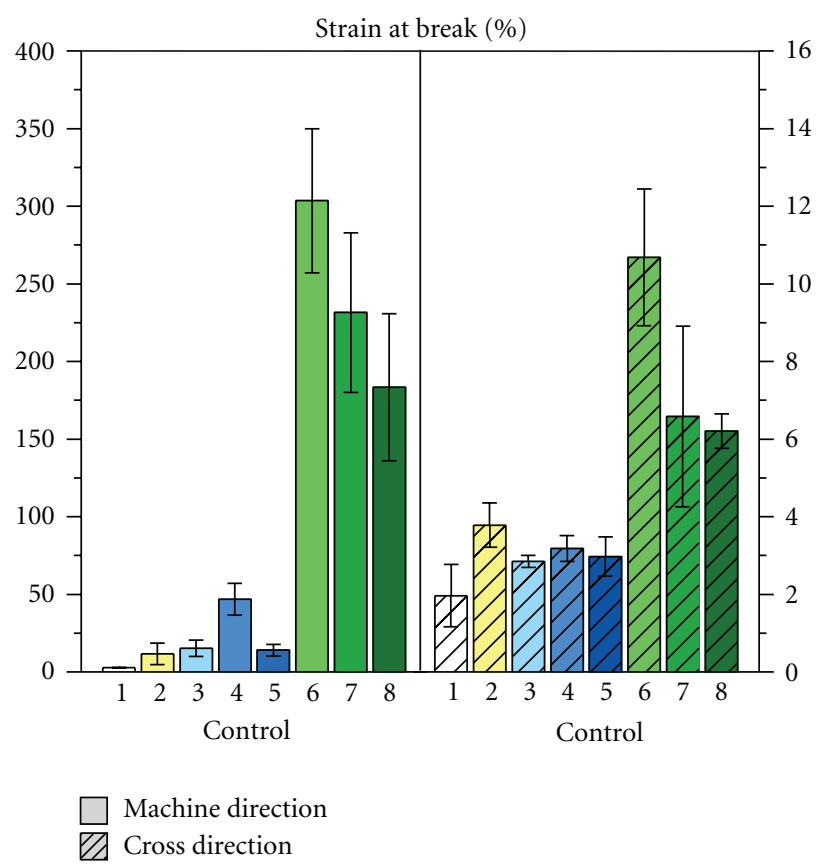

(b)

FIGURE 4: Stress at break and strain at break in machine and in cross directions.

were determined. All results presented are the average values of five measurements.

The thermal properties were determined by differential scanning calorimetry (DSC) using Perkin Elmer DSC 7 calorimeter. Each sample was heated from ambient temperature to $200^{\circ} \mathrm{C}$ at a rate of $5^{\circ} \mathrm{C} / \mathrm{min}$ under inert condition; curves obtained from second heating were analyzed. The degree of crystallinity was calculated from the following (1):

$$
x_{c}(\%)=100 \times \frac{\left|\Delta H_{m}+\Delta H_{\mathrm{cc}}\right|}{\Delta H_{m}^{\circ}},
$$




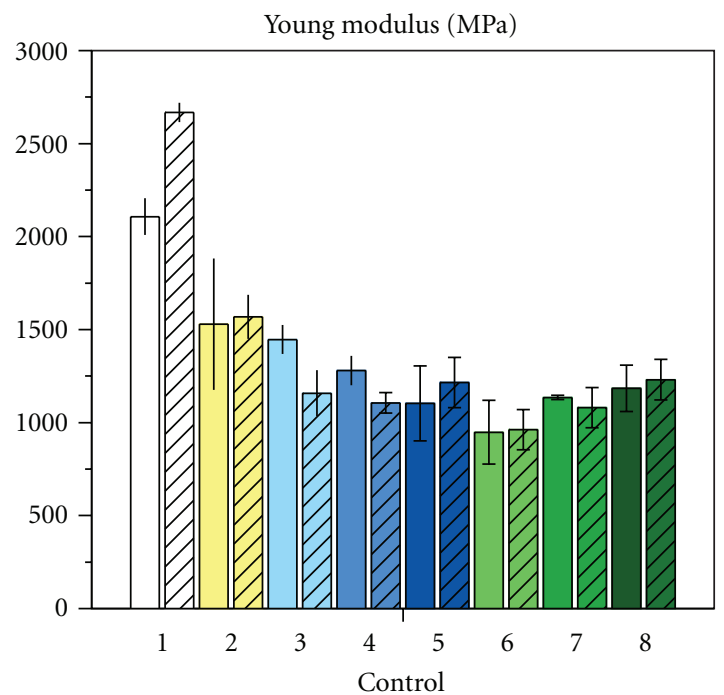

$\square$ Machine direction
$\square$ Cross direction

(a)

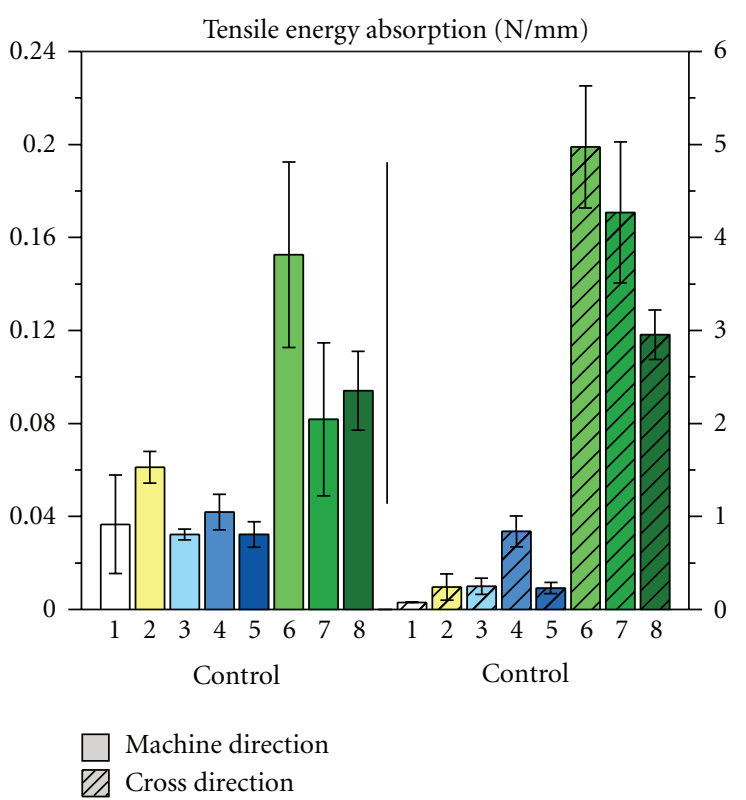

(b)

FIGURE 5: Young modulus and tensile energy absorption in machine and in cross directions.

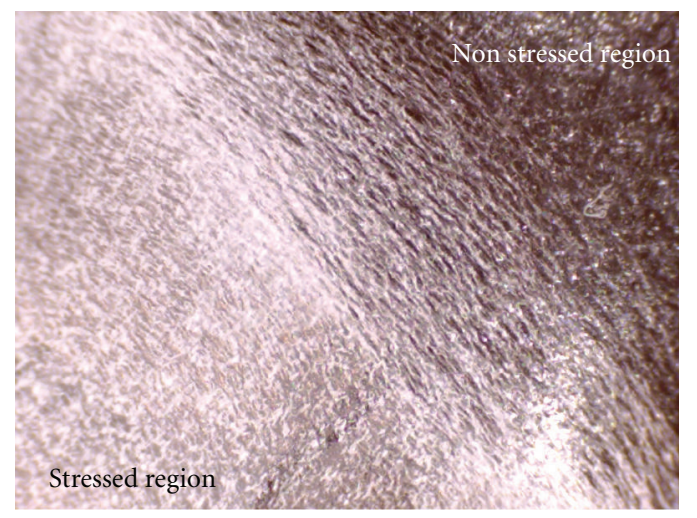

(a)

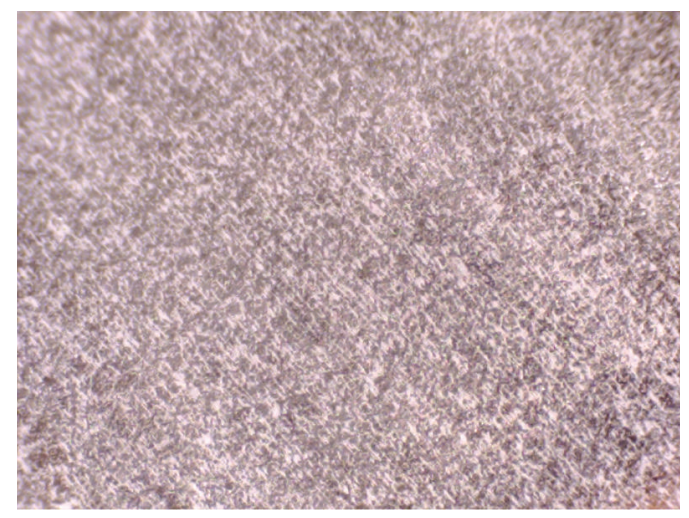

(b)

FIGURE 6: Optical microscopic images of the stress whitening (a) comparison of nonstressed and stressed regions, (b) closer view of the microvoid formation.

TABLE 2: Thermal properties measured by DSC.

\begin{tabular}{lcccccc}
\hline & $T_{m}$ melt peaks $\left({ }^{\circ} \mathrm{C}\right)$ & $T_{g}\left({ }^{\circ} \mathrm{C}\right)$ & $T_{\mathrm{cc}}\left({ }^{\circ} \mathrm{C}\right)$ & $\Delta H_{m}(\mathrm{~J} / \mathrm{g})$ & $\Delta H_{\mathrm{cc}}(\mathrm{J} / \mathrm{g})$ & $x_{c}(\%)$ \\
\hline$(1)$ & 143.5 & 151.6 & 43.9 & 102.8 & 33.76 & 21.41 \\
$(2)$ & 134.2 & 150.1 & 41.2 & 97.3 & 31.46 & 7.95 \\
$(3)$ & 138.6 & 150.7 & 40.9 & 92.8 & 28.29 & 13.19 \\
$(4)$ & 135.4 & 149.9 & 41.5 & 83.4 & 27.48 & 25.12 \\
$(5)$ & 137.2 & 150.1 & 42.0 & 88.6 & 28.74 & 6.64 \\
$(6)$ & 137.8 & 150.3 & 41.1 & 89.7 & 28.89 & 11.30 \\
$(7)$ & - & 150.5 & 42.3 & 90.3 & 29.24 & 9.17 \\
$(8)$ & 138.6 & 150.5 & 42.5 & 91.6 & 30.11 & 7.52 \\
\hline
\end{tabular}




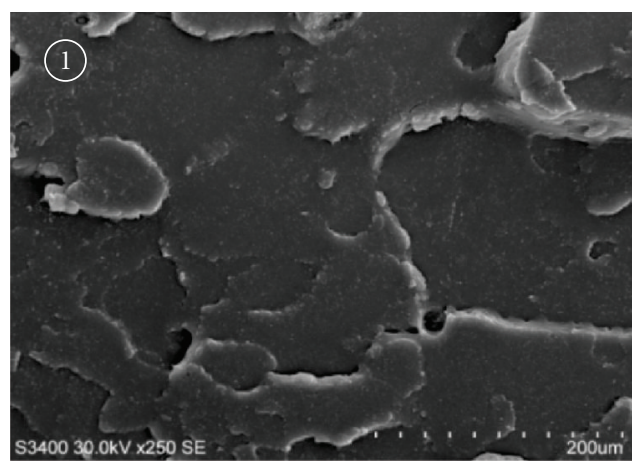

(a)

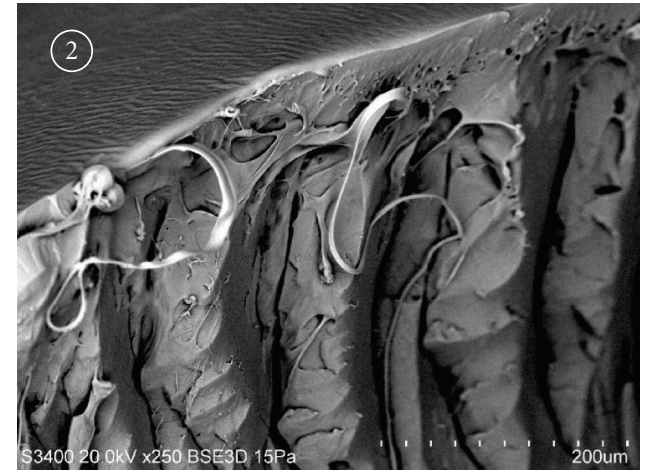

(b)

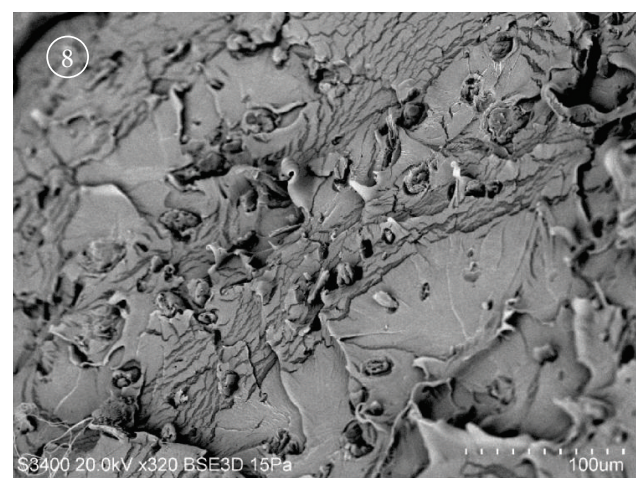

(c)

FIGURE 7: SEM micrographs of the tensile fractured surfaces.

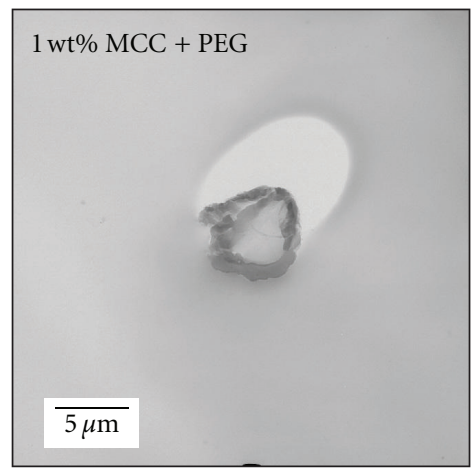

(a)

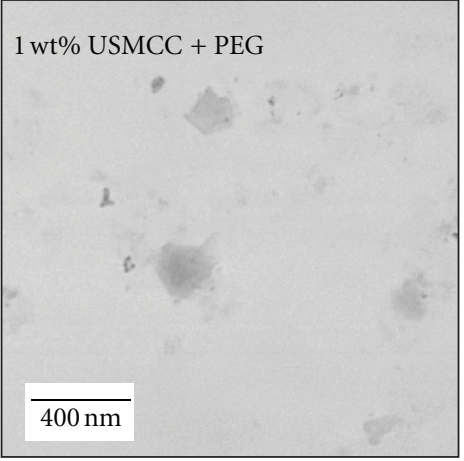

(d)

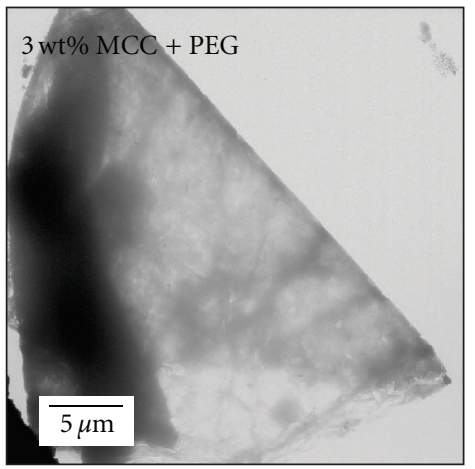

(b)

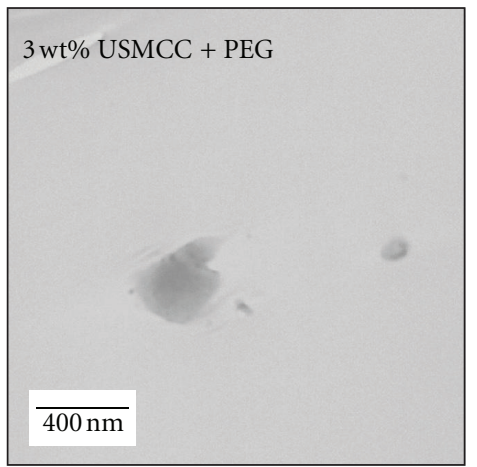

(e)

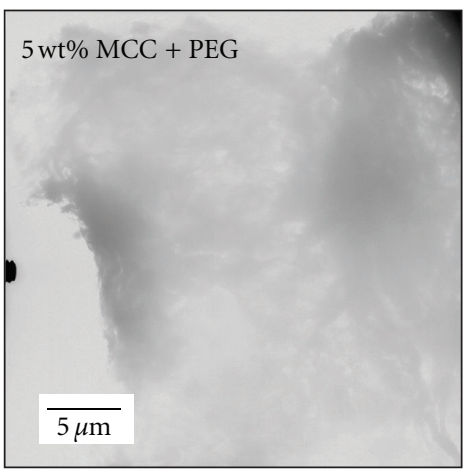

(c)

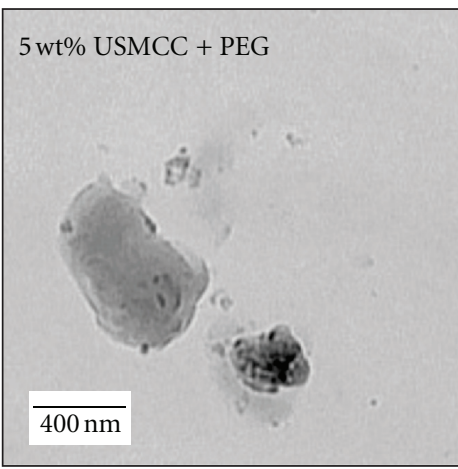

(f)

FIgURE 8: TEM images of the modified samples. 


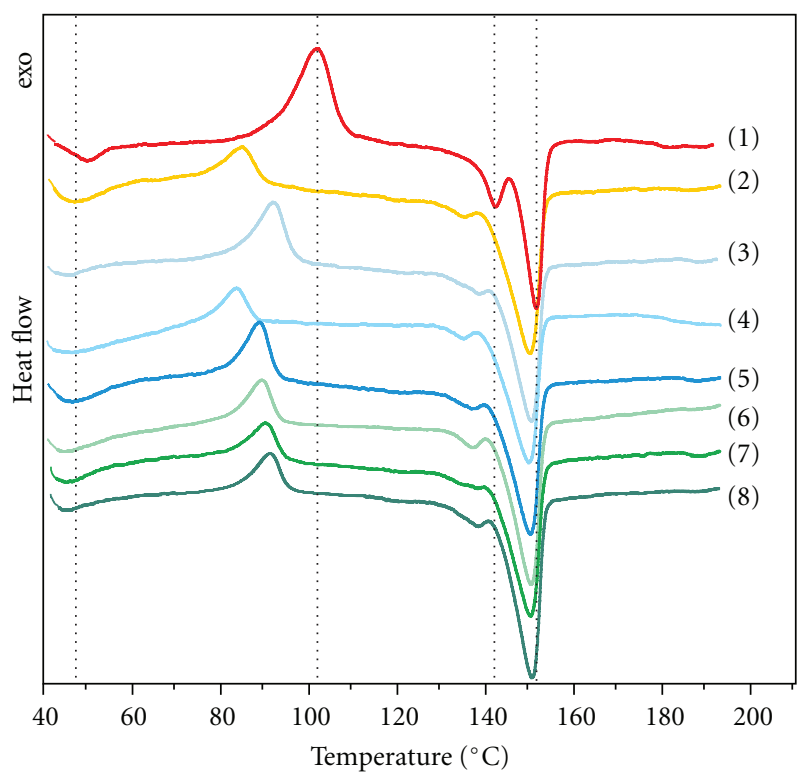

FIgURE 9: DSC curves of neat PLA and PLA-based samples.

where $\Delta H_{m}$ and $\Delta H_{\mathrm{cc}}$ are the enthalpy of fusion and crystallization at melting and crystallization temperature, respectively. $\Delta H_{m}^{\circ}$ is the heat of fusion of a perfect orthorhombic PLA crystal with applying the value of $93.6 \mathrm{~J} / \mathrm{g}$.

In order to investigate the microstructure of the samples scanning electron microscopy (SEM) (Hitachi S-3400N) was used. The secondary electron images were taken of the fracture surfaces. The acceleration voltage was $20 \mathrm{kV}$, and the specimens were coated with gold to avoid charging.

Transmission electron microscopy (TEM) of the ultrathin PLA-based samples was carried out with Jeol JEM-2000EX transmission electron microscope. The acceleration voltage was $120 \mathrm{keV}$.

Wide-angle X-ray (WAXD) scattering measurements were carried out with a Philips PW1710 diffractometer. WAXD patterns were obtained at room temperature using nickel-filtered $\mathrm{Cu} \mathrm{K} \alpha$ radiation with generator tension of $50 \mathrm{kV}$, generator current of $40 \mathrm{~mA}$, and a wavelength of $0.1544 \mathrm{~nm}$, in range of $5-40^{\circ} 2 \theta$.

Degradation test was performed under industrial composting condition with temperature of $58^{\circ} \mathrm{C}$ and moisture content of $60 \mathrm{wt} \%$. The test was performed for 45 days.

\section{Results and Discussions}

Stress-strain curves of the neat and the modified samples in machine and in cross directions are shown in Figures 1 and 2. According to the results neat PLA showed no necking; it had broken with very little elongation, and it exhibited no or little plastic deformations. On the other hand most of the modified samples containing PEG400 and cellulose showed plastic deformation with yielding. The maximal improvement at machine direction in strain at peak (Figure 4) was 106\% (strain was $4.2 \%$ ) in case of PLA containing $1 \mathrm{wt} \%$ USMCC with PEG; at cross section sample with the same composition

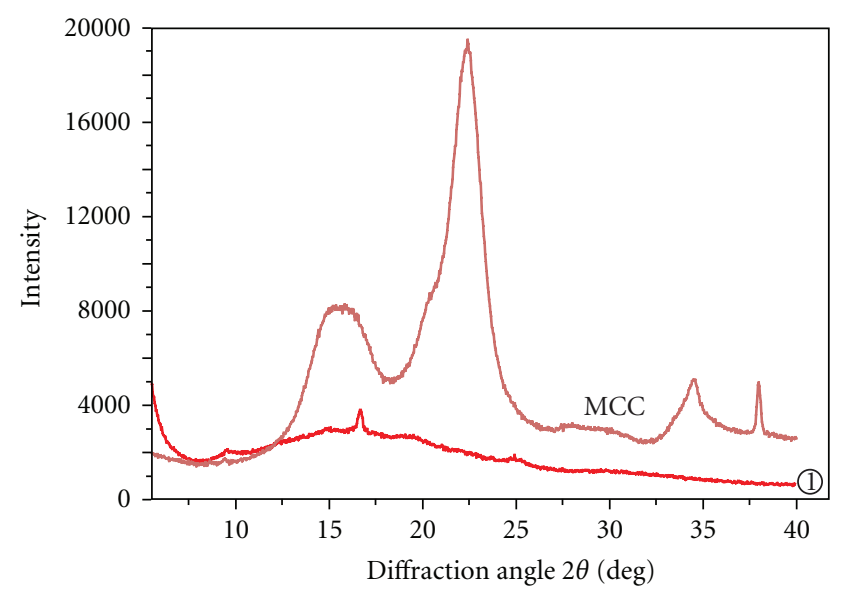

(a)

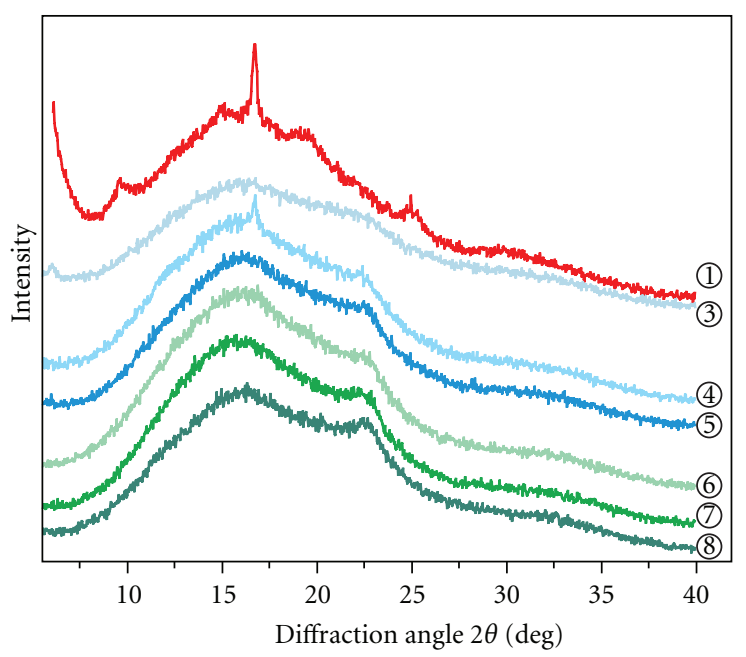

(b)

FIgURE 10: Diffraction patterns of MCC, neat PLA, and PLA-based composites.

showed the highest improvement (113\%), where the strain was $4.178 \%$. More remarkable improvement was observed in case of strain at break (Figure 5), where samples with UStreated MCC showed significant enhancement at machine and cross directions as one can see in Figures 1 and 2. The strains at break in the machine direction are 303.5, 236.0\%, and $183.4 \%$ in case of using 1,3 , and $5 \mathrm{wt} \%$ of USMCC with $10 \mathrm{wt} \%$ of PEG, respectively. The neck which was formed during strain softening extended along these samples, and large amount of cold drawing occurred with little strain hardening. The high srain-to-failure and the high thoroughness were mainly due to void formation which was indicated by stress whitening [24, 25] (Figure 6). The microvoids release the plastic constraint in the matrix, triggering large-scale plastic deformations [25]. The incorporated particles cavitate in the matrix that adsorbs higher energies (Cotterell [26]) which resulted in improvement of tensile energy absorption (Figure 5). The tensile energy absorption was enhanced almost in every case (excluded samples containing 1 and $5 \mathrm{wt} \%$ MCC and PEG400 without ultrasound treatment). The explanation 


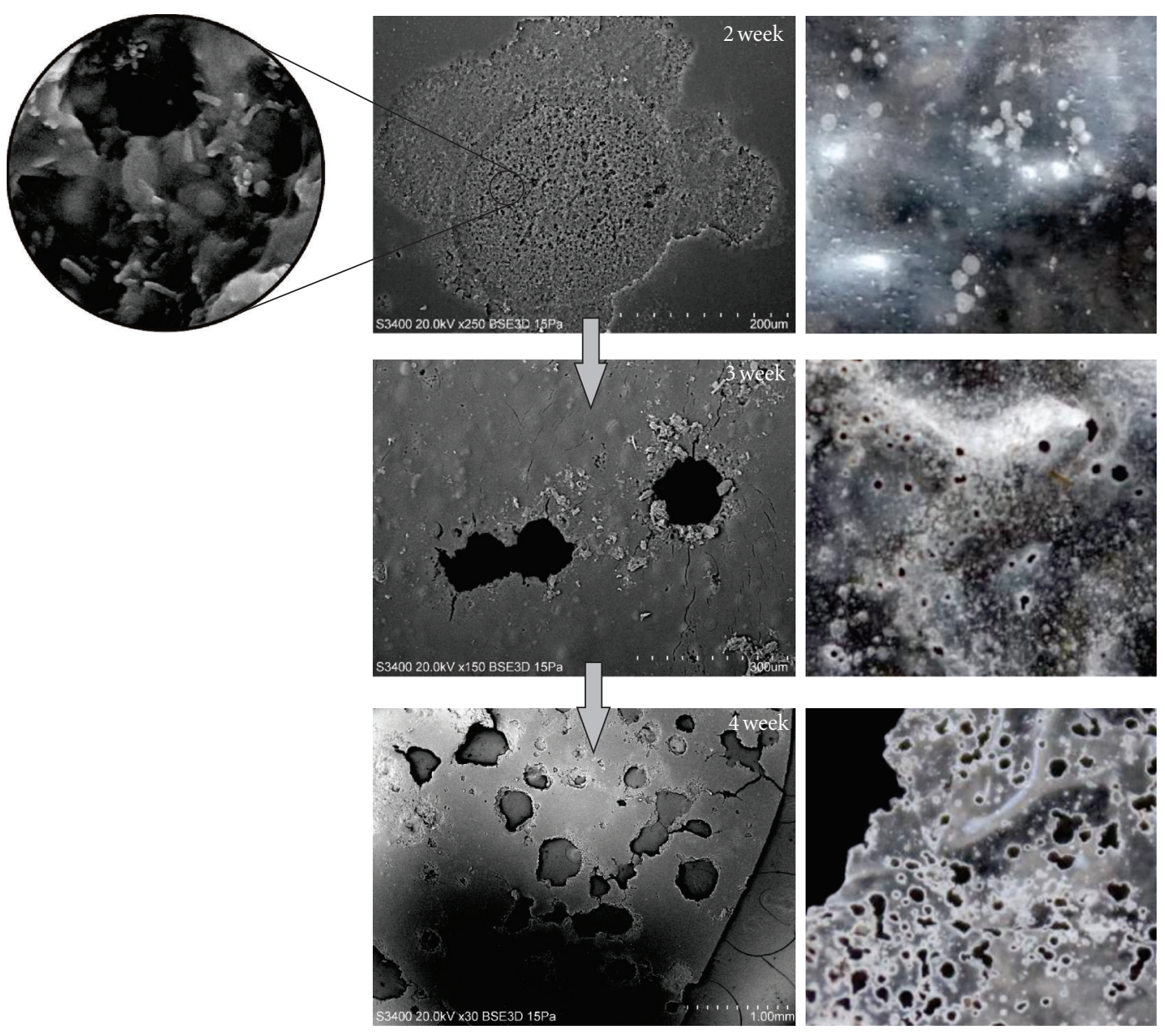

FIGURE 11: SEM and photo images of degradation mechanism of PLA films under composting condition.

of the higher strain and energy absorption of the samples modified with ultrasound-treated cellulose lies on the fact that the treatment resulted in fine particles formation. The smaller cellulose particles have got higher surface area which provides the possibility of better adhesion in the interface. Although strain at break was improved, stress at peak (Figure 3 ), ultimate strength (Figure 4) and Young-modulus (Figure 5) were reduced as expected.

Scanning electron microscopic (SEM) images (Figure 7) were taken of the facture surfaces after the tensile tests. As the images demonstrate the neat PLA shows rigid broken surface; no plastic regions can be observed. In contrast sample containing PEG 400 shows plastic deformations as well as the other modified samples. MCC particles can be clearly seen in the fracture surfaces, but the dispersion and the distribution are optimal. Although samples with US treatment contain microsized particles, which involves that the size reduction was not complete, other results indicate that the samples contain smaller particles as well.

After cutting ultrathin films of the composites transmission electron microscopy (TEM) was carried out. In Figure 8 cellulose particles can be seen in the poly(lactic acid) matrix, the less the concentration of the MCC-PEG suspension was the more effective the US treatment became. There are small particles under $100 \mathrm{~nm}$ in the composites containing USMCC. Because of the sensitivity of the PLA to the relative high-acceleration voltage closer images could not be taken.

DSC measurement (Figure 9 and Table 2) was used to characterize the thermal properties of neat PLA, and PLAbased composites. Glass transition temperatures $\left(T_{\mathrm{g}}\right)$ of the modified materials were decreased or cannot be observed due to the plasticizer which provided more flexibility to the polymer chains. In the DSC heating scans all PLA and PLA-based samples showed exothermic peak which attributed to the cold crystallization $\left(T_{\mathrm{cc}}\right)$. The amorphous part of the modified poly(lactic acid) samples started to form organized structure at lower temperatures $\left(T_{c c}\right)$. Due to the presence of PEG enhanced chain mobility occurred in the amorphous phase, and PLA crystallizes with more ease at lower temperatures. The exothermal cold crystallization peaks are smaller and thinner compared to the neat PLA, but as one can see in some cases the melting peaks are wider indicating higher crystallinity. The melting temperatures did not show notable difference except the difference of the two melting peaks. While the neat PLA bears two well-defined individual peaks, the first melting peaks of the composites are not so strong, and they shifted to lower temperatures. The two melting peaks of neat PLA can be due to the coexistence 
of two kind of crystalline structure or because of the melting behavior with melt recrystallization model $[27,28]$ or due to the dual lamellae population [28]. The smaller peaks can indicate that the plasticizer and the additives changed the crystal structure of the PLA (in case of (7) no other peak can be observed). According to the enthalpies and the calculated crystallinity the cellulose may act as nucleating agent especially when untrasonical treatment was used. Pei et al. [29] reported that the nucleating effect is enhanced if homogenous cellulose dispersion in poly(lactic acid) matrix is achieved. This indicates that more homogenous structure was obtained with US treatment which modified the cellulose characteristics as well and probably caused significant size reduction.

The WAXD diffractograms are shown on Figure 10. On Figure 10(a) the WAXD pattern of the neat PLA and MCC, and on Figure 10(b) the WAXD pattern of the composite materials comparing to the neat PLA are presented. The neat PLA shows four main peaks which can be corresponded to the different crystal structures. The peak at $2 \theta=16.7^{\circ}$ (5.304 $\AA$ Á) is the peak of homocrystal form, while the other peaks $\left(2 \theta=9.5^{\circ}, 16.7^{\circ}, 19.5^{\circ}, 24.9^{\circ}-9.230^{\circ}, 4.564^{\circ}\right.$, and $3.521 \AA$, resp.) can be attributed to the stereocomplex crystal form $[30,31]$. The broad hump shows amorphous nature. In case of MCC the peaks that occurred at $2 \theta=9.4^{\circ}, 22.4^{\circ}, 35.00^{\circ}$ $\left(5.676^{\circ}, 3.961^{\circ}, 2.598 \AA\right.$ Á) are corresponding to the cellulose I polymorph structure [11]; a board peak appeared as well at $2 \theta=16.5^{\circ}$. The composites (letters mean the same as in the Table 1) show no peaks but broad hump with shoulder (except in case of PLA containing $3 \mathrm{wt} \%$ MCC and $10 \mathrm{wt} \%$ of PEG where a little peak can be observed at $2 \theta=16.6^{\circ}$ ). Mathew et al. [11] explains that this phenomenon occurs due to the fast cooling rates during extrusion which indicate low crystallinity. The diffractograms show regular trend in the intensity of the shoulder (later board peak); the higher the MCC content the higher the peak formed around at $2 \theta=$ $22.4^{\circ}$; moreover, higher intensity appeared when ultrasound treatment was used, probably due to the higher crystallinity of cellulose caused by the treatment, which degraded some of the amorphous regions in the MCC [15]. The intensity of the peak (which can be originated mainly from the PLA crystallinity but from the MCC as well) around $2 \theta=16.7^{\circ}$ on the other hand does not show any regular trends in intensity change.

The degradation rates of modified samples were slightly faster than the rate of neat PLA. For the day 45 all the samples fragmented and became invisible to the naked eyes. During the degradation test scanning electron microscopic images were done. In Figure 11 degradation process can be seen. After 14 days white dots appeared on the sample surfaces, which were contributed to the activity of the microorganisms. The SEM images proved that the degradation of PLA was truly biodegradation; the tiny bacteria can be clearly seen in the images. The small dots became small holes as time went by; the holes together formed bigger holes, and finally the samples fragmented into small, invisible pieces or they totally biodegraded.

\section{Conclusions}

During this research MCC, ultrasound-treated MCC, and PEG 400 were used to modify the properties of the PLA. According to the results small amount (1 wt\%) of US-treated cellulose in PEG 400 was enough to reduce remarkably the brittleness of the PLA and to create a though material. Slighter improvement occurred when PEG400 or MCC with PEG400 was only used. The thermal properties of the foils did not change significantly except the cold crystallization temperature which shifted to lower values attributed to chain mobilizing effect of the plasticizer. The presence of PEG400 and MCC and especially the US-treated MCC indicated higher crystallinity. Although amorphous characteristic was stronger probably due to the fast cooling rates during the film extrusion process, XRD results showed enhancement in the crystallinity of cellulose which was attributed to the ultrasound treatment. While SEM images showed that microsized cellulose particles still remained (despite the US treatment) TEM images proved that the size of the particles was reduced remarkably too. Possibly a hybrid of microand nanocomposite was formed. Although further research is needed to improve the compatibility between cellulose and PLA, materials in micro- and nanosize derived from cellulose could play a large role in the improvement of PLA.

\section{Acknowledgment}

This work was supported in part by Development of Student Talent Fostering at WHU, TAMOP 4.2.2.B-10/1-2010 Project sponsored by the EU/European Social Foundation.

\section{References}

[1] A. M. Gajria, V. Davé, R. A. Gross, and S. P. McCarthy, "Miscibility and biodegradability of blends of poly(lactic acid) and poly(vinyl acetate)," Polymer, vol. 37, no. 3, pp. 437-444, 1996.

[2] O. Martin and L. Avérous, "Poly(lactic acid): plasticization and properties of biodegradable multiphase systems," Polymer, vol. 42, no. 14, pp. 6209-6219, 2001.

[3] N. Ljungberg and B. Wesslén, "The effects of plasticizers on the dynamic mechanical and thermal properties of poly(lactic acid)," Journal of Applied Polymer Science, vol. 86, no. 5, pp. 1227-1234, 2002.

[4] R. M. Rasal, A. V. Janorkar, and D. E. Hirt, "Poly(lactic acid) modifications," Progress in Polymer Science, vol. 35, no. 3, pp. 338-356, 2010.

[5] S. S. Ray, P. Maiti, M. Okamoto, K. Yamada, and K. Ueda, "New polylactide/layered silicate nanocomposites. 1. Preparation, characterization, and properties," Macromolecules, vol. 35, no. 8, pp. 3104-3110, 2002.

[6] M. Pluta, J. K. Jeszka, and G. Boiteux, "Polylactide/montmorillonite nanocomposites: structure, dielectric, viscoelastic and thermal properties," European Polymer Journal, vol. 43, no. 7, pp. 2819-2835, 2007.

[7] W. M. Chiu, Y. A. Chang, H. Y. Kuo, M. H. Lin, and H. C. Wen, "A study of carbon nanotubes/biodegradable plastic polylactic acid composites," Journal of Applied Polymer Science, vol. 108, no. 5, pp. 3024-3030, 2008. 
[8] H. Balakrishnan, A. Hassan, M. U. Wahit, A. A. Yussuf, and S. B. A. Razak, "Novel toughened polylactic acid nanocomposite: mechanical, thermal and morphological properties," Materials and Design, vol. 31, no. 7, pp. 3289-3298, 2010.

[9] E. Fortunati, I. Armentano, Q. Zhou et al., "Multifunctional bionanocomposite films of poly(lactic acid), cellulose nanocrystals and silver nanoparticles," Carbohydrate Polymers, vol. 87, pp. 1596-1605, 2012.

[10] M. N. Belgacem and A. Gandini, "The surface modification of cellulose fibres for use as reinforcing elements in composite materials," Composite Interfaces, vol. 12, no. 1-2, pp. 41-75, 2005.

[11] A. P. Mathew, K. Oksman, and M. Sain, "Mechanical properties of biodegradable composites from poly lactic acid (PLA) and microcrystalline cellulose (MCC)," Journal of Applied Polymer Science, vol. 97, no. 5, pp. 2014-2025, 2005.

[12] L. Petersson and K. Oksman, "Biopolymer based nanocomposites: comparing layered silicates and microcrystalline cellulose as nanoreinforcement," Composites Science and Technology, vol. 66, no. 13, pp. 2187-2196, 2006.

[13] P. Qu, Y. Gao, G. F. Wu, and L. P. Zhang, "Nanocomposites of Poly(lactic acid) reinforced with cellulose nanofibrils," Bioresources, vol. 5, no. 3, pp. 1811-1823, 2010.

[14] M. N. Belgacem and A. Gandini, Monomers, Polymers and Composites from Reneawable Resources, Elsevier, Oxford, UK, 2008.

[15] P. B. Filson and B. E. Dawson-Andoh, "Sono-chemical preparation of cellulose nanocrystals from lignocellulose derived materials," Bioresource Technology, vol. 100, no. 7, pp. 2259-2264, 2009.

[16] D. V. Pinjari and A. B. Pandit, "Cavitation milling of natural cellulose to nanofibrils," Ultrasonics Sonochemistry, vol. 17, no. 5, pp. 845-852, 2010.

[17] D. J. Gardner, G. S. Oporto, R. Mills, and M. A. S. A. Samir, "Adhesion and surface issues in cellulose and nanocellulose," Journal of Adhesion Science and Technology, vol. 22, pp. 545-567, 2008.

[18] K. Renner, J. Moczó, and B. Pukánszky, "Micromechanical deformations in particulate filled polymers: the effect of adhesion," in Proceeding of the 17th International Conference on Composite Materials, 2009.

[19] N. Nakayama and T. Hayasi, "Preparation and characterization of poly(L-lactic acid)/TiO 2 nanoparticle nanocomposite films with high transparency and efficient photodegradability," Polymer Degradation and Stability, vol. 92, no. 7, pp. 1255-1264, 2007.

[20] M. Baiardo, G. Frisoni, M. Scandola et al., "Thermal and mechanical properties of plasticized poly(L-lactic acid)," Journal of Applied Polymer Science, vol. 90, no. 7, pp. 1731-1738, 2003.

[21] N. Cao, X. Yang, and Y. Fu, "Effects of various plasticizers on mechanical and water vapor barrier properties of gelatin films," Food Hydrocolloids, vol. 23, no. 3, pp. 729-735, 2009.

[22] L. Yang and A. T. Paulson, "Effects on mechanical and moisture barrier properties of edible gellan film," Food Research International, vol. 33, no. 7, pp. 571-578, 2000.

[23] L. T. Lim, R. Auras, and M. Rubino, "Processing technologies for poly(lactic acid)," Progress in Polymer Science, vol. 33, no. 8, pp. 820-852, 2008.

[24] F. Ali, Y. W. Chang, S. C. Kang, and J. Y. Yoon, "Thermal, mechanical and rheological properties of poly (lactic acid)/epoxidized soybean oil blends," Polymer Bulletin, vol. 62, no. 1, pp. 91-98, 2009.

[25] B. Gurun, Defromation Studies of Polymers and Polymer/Clay Nanocomposites, Dissertation, Georgia Institute of Techology, 2010.

[26] B. Cotterell, J. Y. H. Chia, and K. Hbaieb, "Fracture mechanisms and fracture toughness in semicrystalline polymer nanocomposites," Engineering Fracture Machanics, vol. 74, no. 7, pp. 1054-1078, 2007.

[27] M. Yasuniwa, S. Tsubakihara, Y. Sugimoto, and C. Nakafuku, "Thermal analysis of the double-melting behavior of poly $(\mathrm{L}-$ lactic acid)," Journal of Polymer Science B, vol. 42, no. 1, pp. 25-32, 2004

[28] M. Radjabian, M. H. Kish, and N. Mohammadi, "Characterization of poly(lactic acid) multifilament yarns. I. The structure and thermal behavior," Journal of Applied Polymer Science, vol. 117, no. 3, pp. 1516-1525, 2010.

[29] A. Pei, Q. Zhou, and L. A. Berglund, "Functionalized cellulose nanocrystals as biobased nucleation agents in poly(1lactide) (PLLA) - crystallization and mechanical property effects," Composites Science and Technology, vol. 70, no. 5, pp. 815-821, 2010.

[30] Y. Furuhashi and N. Yoshie, "Stereocomplexation of solventcast poly(lactic acid) by addition of non-solvents," Polymer International, vol. 60, pp. 301-306, 2012.

[31] X. Chen, J. Kalish, and S. L. Hu, "Structure evolution of $\alpha$ '-phase poly(lactic acid)," Journal of Polymer Science B, vol. 49, pp. 1446-1454, 2011. 

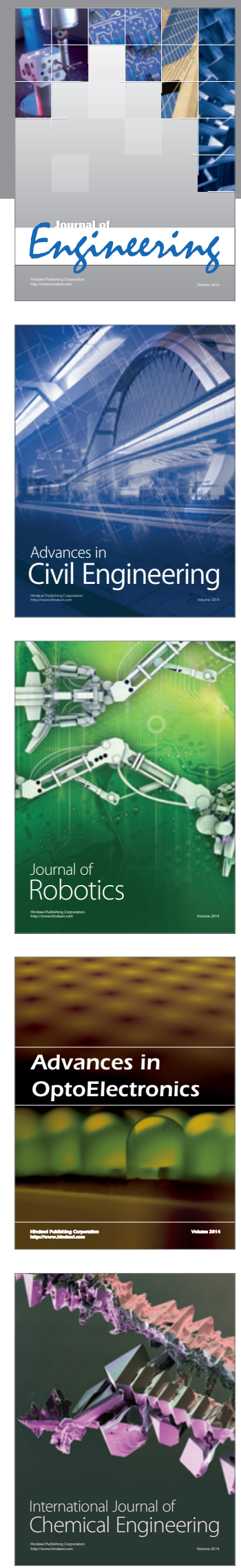

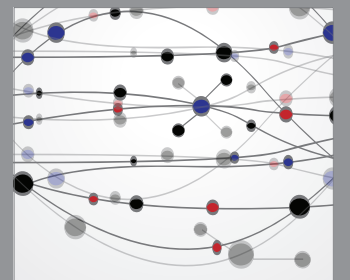

The Scientific World Journal
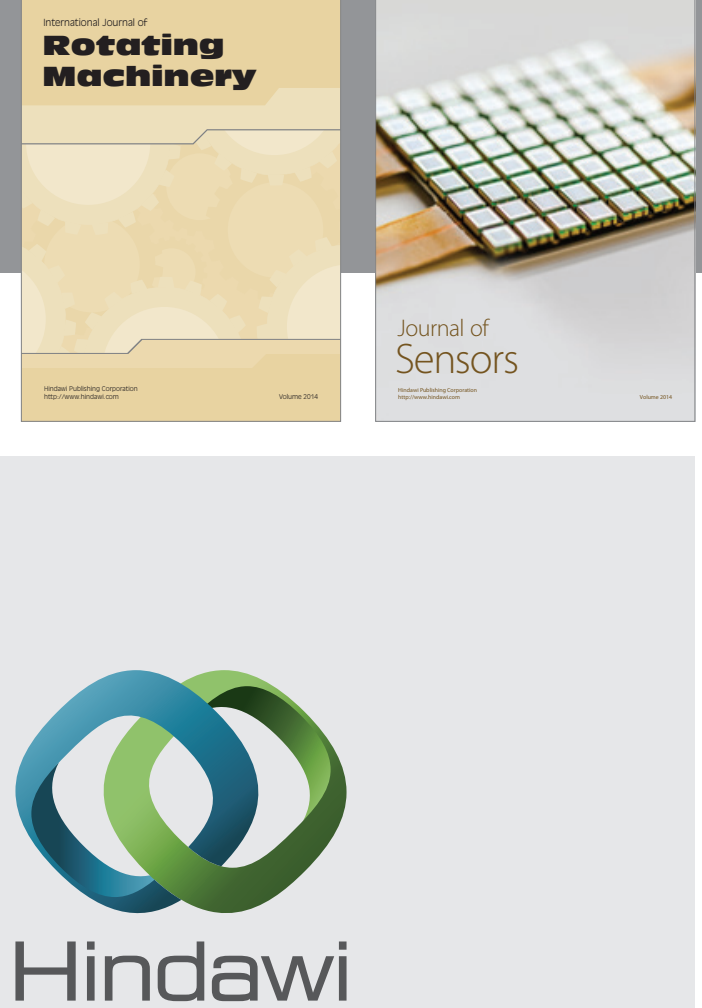

Submit your manuscripts at http://www.hindawi.com
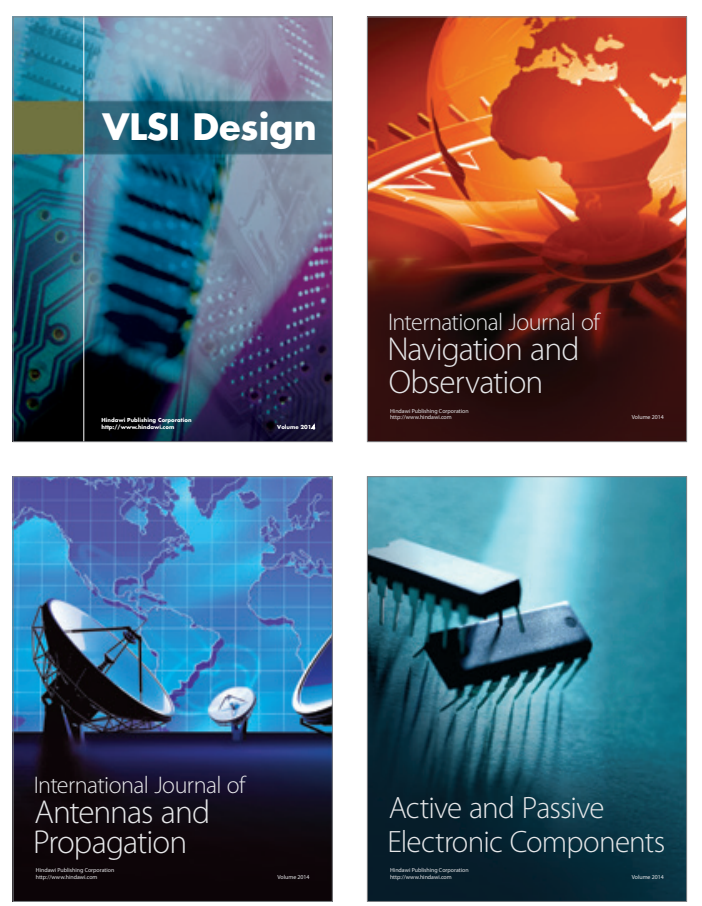
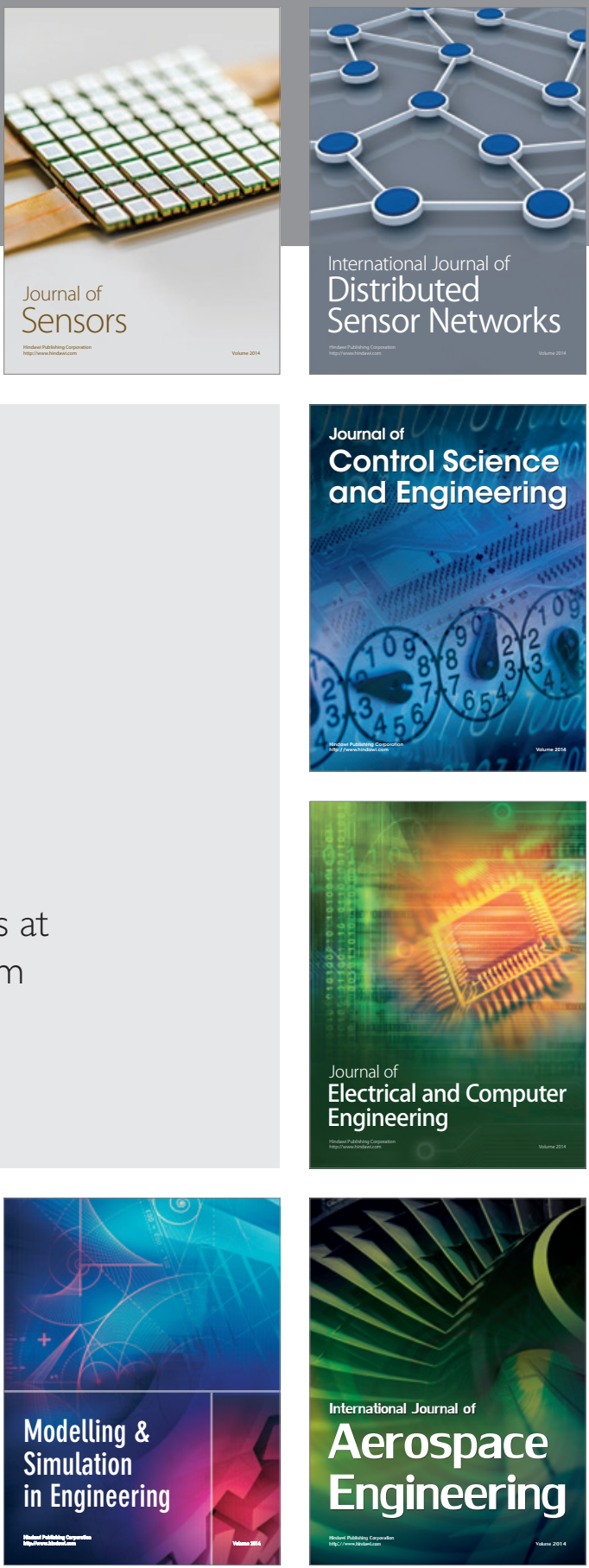

Journal of

Control Science

and Engineering
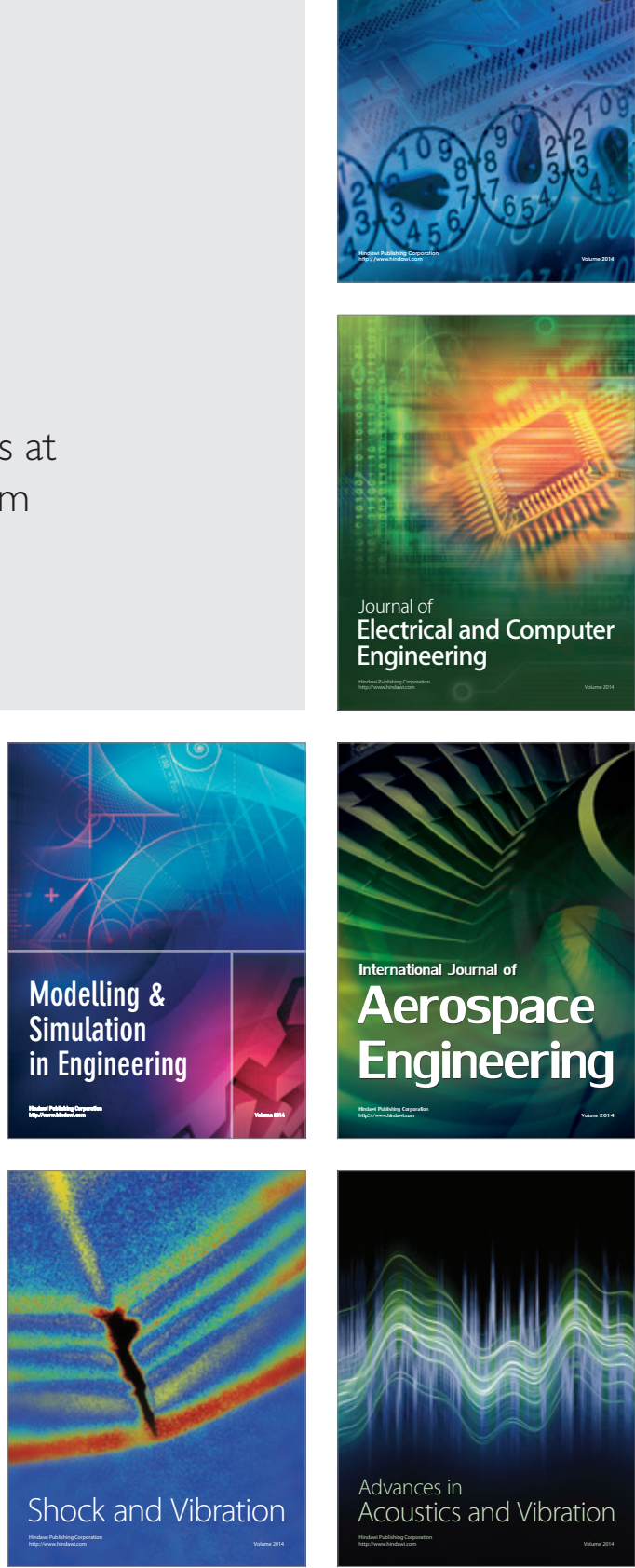